\title{
Convertirse en representante: trayectorias y carreras políticas de diputados nacionales bonaerenses
}

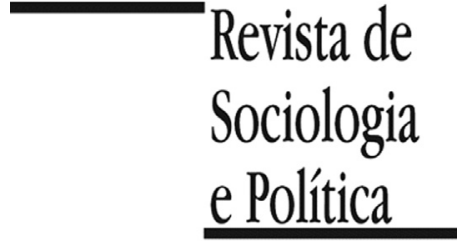

DOI $10.1590 / 1678987318266705$

\section{Cintia Rodrigo id}

RESUMEN Introducción: Este trabajo busca conocer cómo algunos actores políticos logran convertirse en representantes, qué factores les posibilitan el éxito en la competencia. Aborda un elenco político puntual: el de los Diputados Nacionales (DN) por la Provincia de Buenos Aires (PBA), Argentina. El artículo describe dos dimensiones complementarias de sus biografías: sus trayectorias personales y sus carreras políticas previas. El objetivo es conocer si existen formas típicas de articular ambas dimensiones en este territorio particular de producción de lo político. El supuesto central es que no sólo son los partidos — o sus líderes — quienes eligen candidatos, son también - y sobre todo - actores colaborando en redes inestables de cooperación y competencia en distintos niveles quienes dan forma a las estructuras partidarias y/o alianzas electorales que compiten en sucesivas contiendas. Métodos: Los datos presentados provienen de una base de datos inédita que reúne información del universo de 231 diputados nacionales por la PBA del periodo 1999-2015. Resultados: Los resultados muestran dos tipos de articulación entre trayectorias y carreras. Por una parte, convertirse en DN es un modo de acceso frecuente para quienes buscan ser integrados a los elencos legislativos en función de sus vínculos sociales y credenciales educativas, o quienes han acumulado suficientes recursos en otros espacios de participación en la PBA. Por otra, es un punto de llegada para actores que cuentan con un trabajo sostenido de participación, acumulación de destrezas y establecimiento de vínculos en distintos niveles de gobierno. Discusión: La forma en que se articulan trayectorias personales y carreras en este conjunto de actores evidencia que cuentan con grados de autonomía relativa, obtenidos a partir de un trabajo activo, sostenido y prolongado en distintas arenas de participación. Actores que cuentan con recursos propios configuran un elenco legislativo relativamente independiente de lógicas estrictamente dirigenciales. Por el contrario, su propia participación es la que contribuye a la fisonomía que asumen los partidos y/o alianzas y a la dinámica de la competencia política en las distintas escalas. Actores que anclan su legitimidad en el nivel local, representando a un distrito provincial, para desempeñarse en la escala nacional, los DN constituyen un punto de mira privilegiado para pensar la imbricación de las escalas en la política argentina. Una agenda de investigación que abren estos resultados es el análisis de otros distritos subnacionales, a fin comparar modalidades de construcción de distintos elencos legislativos nacionales.

PALABRAS CLAVE: trayectoria política; carrera política subnacional; diputados nacionales; representantes políticos; Provincia de Buenos Aires.

Recibido en 14 de Abril de 2017. Aceptado en 6 de Deciembre de 2017.

\section{Introducción ${ }^{1}$}

1 Agradecemos las sugerencias y comentarios de los dictaminadores anónimos de la Revista de Sociologia e Política.
$\mathrm{E}$ ste trabajo busca conocer cómo algunos actores logran convertirse en representantes. Es una afirmación básica para estudios de cuño weberiano que la actividad política se funda en una lógica de competencia (Weber 1982; 1998). A esta idea base se puede sumar otra: que llegar a ocupar una posición es resultado de un trabajo activo, un trabajo que requiere ser sostenido en el tiempo por ciertos individuos interesados en el juego (Bourdieu 2001a; Fillieule 2015). Desde tales premisas, este artículo se pregunta por los factores que posibilitan el éxito: ¿hay elementos comunes en las biografías de estos actores que les permiten ser exitosos en la competencia? Para dar respuesta a tales interrogantes se aborda un elenco político puntual: el de los Diputados Nacionales (DN) por la Provincia de Buenos Aires (PBA). La propuesta del artículo es describir dos dimensiones complementarias de las biografías de quienes lograron convertirse en representantes: sus trayectorias personales y sus carreras políticas previas. El objetivo es conocer si existen formas típicas de 
${ }^{2}$ En la literatura se encuentran diversas categorías para el abordaje de las trayectorias individuales: orígenes sociales, recursos, atributos biográficos, rasgos biográficos. En este trabajo se opta por la noción de trayectoria individual por considerar que es la más pertinente teóricamente y que es al mismo tiempo lo suficientemente amplia como para incorporar las distintas dimensiones desarrolladas en otros trabajos sobre la temática. articular ambas dimensiones en el territorio particular de producción de lo político que es la PBA.

La pregunta por las características de los sectores dirigentes es cada vez más frecuente en los estudios políticos. Los estudios sobre elites, sectores dirigentes o elencos políticos de Argentina se han convertido en un campo fértil en los últimos años. Si hasta hace poco tiempo se podía constatar un vacío en cuanto a la evidencia en este tipo de análisis, el desarrollo de distintas líneas de trabajo complementarias proporciona actualmente una base cada vez más sólida sobre la cual anclar descripciones de los sectores dirigentes en Argentina. Encontramos trabajos sobre distintos tipos de actores y escalas: ministros (Gené 2010; Giorgi 2014; Heredia 2015), senadores (Canelo 2011; Levita 2015), gobernadores (Lascurain 2011; Campomar \& Suárez 2014; Lodola 2017), vicegobernadores (Suárez 2016), diputados nacionales (Ferrari 2005; 2008; García Arias 2007; Simison 2013; Bieda 2015; Simone 2015), diputados provinciales y concejales (Ferrari 2001; Lodola 2009; Landau 2012; Ortiz de Rozas 2012). También sobre distintos tipos de cargo en una jurisdicción (Rotman \& Varetto 2015) y análisis con perspectiva de género sobre distintos tipos de cargo (Marx, Caminotti \& Borner 2007; Borner et al., 2009; Caminotti, Rotman \& Varetto 2011; Caminotti 2013).

Dos grupos más claros pueden distinguirse dentro de los estudios sobre elencos políticos. Por una parte, el que hace énfasis en las carreras y parte de la noción de ambición, heredera de la obra de Schlesinger (1966), la cual ha sido retomada y complejizada crecientemente en las últimas décadas (Borchert 2009; Samuels 2011). Por otra, trabajos que describen recorridos biográficos de quienes eligen la política como profesión, basados en los trabajos de la sociología política francesa (Gaxie 2004; Offerlé 2011a; 2011b) que son recuperados cada vez más para analizar la profesión política en Latinoamérica (Serna 2005 2009; Botero 2011; Joignant 2012).

Para el caso argentino, y en particular desde un análisis en clave subnacional, los trabajos más recientes sobre elencos políticos legislativos y ejecutivos se estructuran alrededor de las nociones de carrera (descriptas a partir de indicadores tales como posiciones ocupadas y/o movimientos realizados), y/o de trayectoria (operacionalizada como recursos, atributos personales o rasgos biográficos) de distintos tipos de actores ${ }^{2}$.

En cuanto a gobernadores se puede consultar el trabajo de Campomar y Suarez (2014), quienes analizan sus carreras políticas buscando entender el origen de estos líderes, cómo llegaron a ocupar ese cargo y si existe algún tipo de lógica para llegar a ocupar el mismo. Combinan para ello variables institucionales con tipos de ambición. Las carreras se describen en función de indicadores tales como tipos de cargo en el que se inician, niveles por los que transitan y promedio de cargos ocupados.

Por su parte, Lodola (2017) examina de qué manera un conjunto de variables formales relacionadas con la estructura del carrerismo político, e informales vinculadas con los orígenes sociales de los políticos, intervienen en el proceso de reclutamiento de la élite gubernamental. Para examinar las rutas formales e informales de entrada al ejecutivo subnacional describe información biográfica (un conjunto de atributos sociales) que combina con indicadores sobre las carreras políticas (posiciones y candidaturas) de quienes fueron gobernadores en Argentina en el último período democrático. Lo interesante del trabajo es la operacionalización que presenta de ambas variables, y la tipología que desarrolla sobre las carreras de gobernadores. La identificación de perfiles sociales e itinerarios de carrera resultante es un importante insumo para pensar en otros tipos de actores, establecer paralelismos y diferencias. 
${ }^{3}$ Para una reseña de los trabajos sobre legisladores desde una perspectiva nacional ver Rodrigo (2014).
${ }^{4}$ El análisis en clave subnacional implica la puesta en primer plano de la política territorial, que se combina frecuentemente con estudios de caso. La agenda de
Puntualmente sobre elencos legislativos en clave subnacional ${ }^{3}$, se puede consultar el trabajo de Lodola (2009), que construye una tipología de carreras políticas de diputados provinciales. Toma en cuenta para ello dos dimensiones posibles: carrerismo horizontal y carrerismo vertical, y dos modalidades de ambiciones políticas, ambición progresiva y ambición estática. Relaciona de este modo movimientos realizados por actores y estructura de oportunidades políticas disponible, operacionalizando las carreras a partir de los cargos ocupados - tipos, niveles de gobierno, secuencia.

Desde el análisis de trayectorias Landau (2012; 2016) analiza los perfiles de concejales y diputados de la Ciudad de Buenos Aires entre 1983 y 2011 desde una reflexión enfocada en la relación entre actividad, carrera y profesión política. Para ello considera en primer lugar distintas dimensiones de las trayectorias personales (laboral, educativa, familiar), las cuales son puestas en relación con los rasgos de las carreras políticas (cargos ocupados, jerarquía, cantidad de años en la función pública). El análisis realizado toma distancia de la noción de ambición y se enfoca en las maneras en que desarrollan las trayectorias individuales y su articulación con carreras más o menos exitosas.

Abordando otro distrito provincial, Ortiz de Rozas (2011) estudia las modalidades de acceso de los diputados provinciales a sus cargos en Santiago del Estero a partir del análisis de sus trayectorias. La autora elabora una tipología de formas de acceso a la Cámara Legislativa, donde enumera recursos necesarios para acceder a una banca: confianza, cercanía o establecimiento de vínculos con aquellos que forman parte del poder político y fundamentalmente ser un dirigente representativo. El caso que presenta que permite trazar un paralelo con la PBA: un distrito cuyo oficialismo resulta "invencible", aunque el mantenimiento del color político tiene como sustrato sucesivas transformaciones de las estructuras y jerarquías partidarias, en las cuales inciden los recorridos personales de quienes compiten para convertirse en representantes.

Específicamente para la PBA, Caminotti, Rotman y Varetto (2011) reconstruyen y analizan perfiles de carrera política todas las personas que ejercieron cargos legislativos nacionales y provinciales, la gobernación y vicegobernación, la titularidad de ministerios provinciales e intendencias municipales a lo largo del período considerado 1983 y 2007. Su objetivo es examinar las oportunidades políticas desde el prisma de la igualdad de género en el acceso a cargos de gobierno. A partir de un análisis de los cargos ocupados y los movimientos realizados el trabajo concluye en que las carreras presentan un perfil generizado en la PBA siendo las mujeres quienes desarrollan carreras más orientadas a cargos legislativos mientras los varones desempeñan la mayor parte de los cargos ejecutivos.

Finalmente Rotman y Varetto (2015) trabajan sobre las particularidades de las carreras políticas de distintos tipos de actores. Analizan los recorridos que se reiteraron que permiten observar la existencia de trayectorias típicas. Su trabajo se ocupa de titulares de los distintos cargos locales, provinciales y nacionales y busca develar la morfología de las estructuras de incentivos en las que se mueven estos actores. Para ello describen los cargos ocupados por estos distintos tipos de actores, vinculando los recorridos con la estructura de incentivos existente. El resultado es una tipología de elites político-partidarias que permite contar con información relevante para este distrito.

Este trabajo busca aportar al desarrollo de los estudios sobre elencos legislativos en clave subnacional ${ }^{4}$, retomando tanto la noción de carrera política como la de trayectoria. Como se mencionó anteriormente, el objetivo es conocer cómo y porqué algunos actores logran convertirse en representantes, específicamente, DN por la PBA. Es decir, qué variables les han posibilitado el acceso a una banca en el Congreso. Para responder tales interrogantes se recorren y 
investigación en esta clave implica una innovación conceptual y teórica que viene de la mano de las nuevas preguntas de investigación y temas de estudio (Suárez-Cao, Batlle \& Wills-Otero 2017).

\footnotetext{
5 Un indicador de la inestabilidad de tales relaciones, sobre todo en el peronismo, es la presentación de diferentes coaliciones y/o estructuras partidarias en casi todas las elecciones del período. Pauta que puede imputarse, sobre todo en el peronismo, a la existencia de no uno si no varios liderazgos en pugna, los cuales tuvieron mayores o menores niveles de éxito electoral y duración. Al respecto, ver Tabla $1 \mathrm{~A}$ en el Apéndice.

${ }^{6}$ A diferencia de otros trabajos (Lodola 2017; Rotman \& Varetto 2015), el anclaje del análisis en la PBA no implica un interés por el desarrollo de carreras en este territorio puntual, sino en la imbricación de escalas. Es decir, anudar lo subnacional y lo nacional para pensar recorridos de dirigentes, reconociendo la raíz de su legitimidad electoral, pero considerando el carácter de su actuación en el cargo obtenido.

${ }^{7}$ Es importante destacar el carácter voluntario de la encuesta anual realizada por la fundación Directorio Legislativo, la cual registra los datos que los actores mismos deciden compartir. En los casos en que se contaba con información de esa encuesta, se la complementó con otras fuentes disponibles. En otros casos toda la trayectoria debió ser reconstruida en base a fuentes alternativas.
}

articulan dos dimensiones de las biografías de este conjunto de actores: sus trayectorias personales y sus carreras políticas.

Llegar a convertirse en representante requiere de un trabajo constante (Fillieule 2015), un compromiso (Becker 1960) sostenido en el tiempo por parte de quienes llegan a ocupar esa posición. Es decir, ocupar una posición no es otra cosa que resultado del trabajo de actores que compiten por cargos escasos con recursos diversos. Hay diversas maneras de convertirse en profesional (Ferrari 2005), y los caminos por los cuales se transita previamente influyen luego en el modo de "ser" político (Offerlé 2011a). Analizar qué recorridos previos al reclutamiento como candidatos en las listas para DN tuvieron estos dirigentes, en tanto desarrollo de un trabajo individual de acumulación de recursos valiosos, permite enlazar factores institucionales con personales (Gauja 2013). Sobre todo en la PBA, donde el peronismo - que fue oficialismo durante todo el período analizado - se ha entendido desde sus orígenes más como un movimiento que como un partido (Levitsky 2005; Aelo 2010). Es decir, no sólo son los partidos - o sus líderes - quienes eligen candidatos, son también - y sobre todo - actores colaborando en redes inestables de cooperación y competencia (Dobry 1988), quienes dan forma a las estructuras partidarias y/o alianzas electorales que compiten en sucesivas contiendas 5 .

Este trabajo se ocupa de la PBA, un distrito donde las escalas local, provincial y nacional se imbrican de manera particularmente relevante para la dinámica política del país (Rotman et al., 2009; Ollier 2010; Caminotti, Rotman \& Varetto 2011). Por su magnitud y dadas las características del sistema político argentino la PBA tiene el contingente legislativo más numeroso de DN $-27 \%$ - (Rotman \& Varetto 2015). Se trata de dirigentes que son electos para desempeñarse en el nivel nacional, pero hunden la base de su legitimidad electoral en el territorio. Es en ellos en quienes se condensa la articulación de escalas, en los rasgos que presentan en términos de carreras y trayectorias personales reside una de las claves de comprensión de la dinámica política nacional y provincial 6 .

Los datos presentados provienen de una base de datos inédita que reúne información del universo de 231 diputados nacionales por la PBA del periodo 1999-2015, distribuidos en 8 cohortes sucesivas. Si bien se tomaron en cuenta todas las posiciones/escaños ocupados (279), los datos que se presentan corresponden a individuos y no a posiciones (es decir, se suma a quienes asumieron como suplentes, pero no se consideran las duplicaciones por reelección). Las principales fuentes utilizadas para construirla fueron las publicaciones de la Fundación Directorio Legislativo ${ }^{7}$, archivos de la Dirección de Información Parlamentaria y el archivo histórico de la Honorable Cámara de Diputados de la Nación. Información que fue complementada y consolidada a partir de revisión de fuentes tales como los principales diarios nacionales y de la PBA, curricula vitae, páginas web personales, perfiles en redes sociales y entrevistas.

El artículo se organiza en tres secciones. En la primera se describen las trayectorias personales de quienes fueron DN considerando sus características sociodemográficas, credenciales educativas, perfiles ocupacionales y tránsitos por distintos espacios de socialización. En la sección siguiente se analizan los tipos de carrera previa a partir de una serie de indicadores: niveles por los que transitaron, tipo de cargo por el que ingresaron al ámbito político, cantidad de cargos ocupados y duración. La tercera sección describe la relación de ambas dimensiones en carreras atípicas. El apartado final resume los principales hallazgos y esboza una agenda de investigación. 


\section{Trayectorias personales}

${ }^{8} \mathrm{El}$ acceso de las mujeres a las listas ha sido objeto de acciones afirmativas desde hace décadas, y pese a los avances obtenidos en el período analizado su porcentaje no supera en el distrito el "cupo" legal vigente en casi ninguna de las cohortes. Sobre acciones afirmativas y sus resultados en Argentina y la PBA hay vasta producción (Alles 2008; Borner et al., 2009; Caminotti, Rotman \& Varetto 2011; Caminotti 2013).

${ }^{9}$ Una afirmación que se encuentra en los análisis clásicos de Durkheim y es retomada por la sociología política francesa de cuño más reciente (Bourdieu 2001b; Offerlé 2011b) como así también latinoamericana (Barreiro de Sousa Lemos \& Leany 2003; Serna 2005; Joignant 2012; Serna 2012).
En el análisis de las trayectorias, variables como género, edad y lugar de origen resultan útiles para caracterizar en rasgos generales a un elenco político (Ortiz de Rozas 2011; Rotman y Varetto 2015; Lodola 2017). En el caso de quienes llegaron a ser DN por la PBA se advierte que es más factible llegar al cargo siendo varón $(66 \%)^{8}$. Considerando el lugar de origen, la tercera parte de estos dirigentes proviene del conurbano, sólo un $20 \%$ de los principales centros urbanos y casi la mitad procede de localidades medianas o pequeñas del interior de la Provincia. Respecto de la edad, el ingreso más frecuente se registra en el intervalo ente los 40 y los 59 años (68\%). Es decir que se trata principalmente de hombres de mediana edad con lazos territoriales.

Otros aspectos que pueden condicionar el modo de acceder a una banca son el background educativo y los espacios de socialización transitados ${ }^{9}$. Por una parte, las credenciales educativas son indicadores de acumulación de capital cultural -legítimo- y también de construcción de vínculos sociales. En este tipo de dirigentes las credenciales educativas son heterogéneas: si bien la mayoría cuenta con estudios universitarios o de posgrado (61\%), un grupo considerable accede a la banca contando con secundario como máximo nivel educativo alcanzado (20\%) (Tabla 1).

Por otra parte, el área de conocimiento, disciplina y tipo de saber privilegiado en las carreras universitarias o terciarias estudiadas expresan la adquisición de competencias más o menos específicas para la actividad legislativa. Serna (2012) señala que la incorporación de saberes jurídicos es la credencial educativa de mayor afinidad electiva con la profesión política en los países del Cono Sur, confirmando la clásica afirmación weberiana. Esto se verifica en la PBA, donde el título de grado en derecho es el más frecuente entre quienes fueron DN (46\%) (Tabla 2).

Es posible advertir en cuanto a la elección del lugar de estudio que la mayoría se graduó en instituciones públicas, ya sean de carácter universitario o terciario. Entre ellos se destaca la Universidad de Buenos Aires (33\%), tal como sucedió entre parlamentarios bonaerenses en otros períodos (Cantón 1966; Ferrari 2008), seguida de la Universidad Nacional de La Plata, de creación más reciente pero que comparte un perfil tradicional en la formación de dirigentes de la Provincia.

También en términos de background es posible afirmar que lo que son en su oficio como políticos depende - aunque no mecánicamente — de lo que fueron en su trayectoria anterior (Offerlé 2011a). En este sentido se puede afirmar que la trayectoria laboral puede ser un factor relevante para comprender los modos de acceso a una banca. De la evidencia se desprende que prima el ejercicio de profesiones liberales $(33.5 \%)$, manteniéndose un rasgo descrito para cohortes previas en la PBA (Rehren 2001; García Arias 2007), aunque también son

Tabla 1 - Máximo nivel educativo completo, DN por la PBA (1999-2015)

\begin{tabular}{lc}
\hline Nivel educativo & Porcentaje \\
\hline Posgrado & 12,8 \\
Universitario & 49,1 \\
Terciario & 17,4 \\
Secundario & 20,6 \\
Total & 100 \\
\hline
\end{tabular}

Fuente: Elaboración propia en base a datos de la autora. 
Tabla 2 - Tipo de carrera universitaria o terciaria, DN por la PBA (1999-2015)

\begin{tabular}{lc}
\hline Carrera & Porcentaje \\
\hline Universitaria & 46,2 \\
Abogacía & 2,3 \\
Arquitectura & 6,9 \\
Ciencias Económicas & 3,5 \\
Ciencias Políticas & 2,9 \\
Psicología & 3,5 \\
Medicina & 3,5 \\
Ingeniería & 8,7 \\
Otra universitaria & \\
Terciaria & 5,8 \\
Profesorado & 2,9 \\
Magisterio & 0 \\
Psicología social & 13,3 \\
Otra terciaria & 100 \\
Total &
\end{tabular}

Fuente: Elaboración propia en base a datos de la autora.

importantes las cifras de empleados privados, docentes y empresarios que llegaron al cargo en este período (Gráfico 1).

Otra dimensión de las trayectorias personales que puede incidir en los modos de acceso a una banca es la participación en organizaciones sociales, dado que cuales constituyen un espacio de socialización, generación de vínculos y/o adquisición de notoriedad (Serna 2005).

${ }^{10}$ Para relevar este tipo de actividad se consideró a las organizaciones en función de sus objetivos: sindical, educativa, cultural, religiosa, asistencial, de derechos humanos, movimientos sociales.
Si bien es un dato de difícil acceso ${ }^{10}$, la participación en distinto tipos de organizaciones sociales aparece como un rasgo en más de la mitad de las trayectorias relevadas $(52.8 \%)$. La participación sindical, ya sea en gremios relativos a la actividad privada (UOM, Ferroviarios, recolección de basura), o estatal (docentes mayormente), es la modalidad más frecuente (27\%). En

Gráfico 1 - Tipo de ocupación previa al cargo, DN por la PBA (1999-2015)

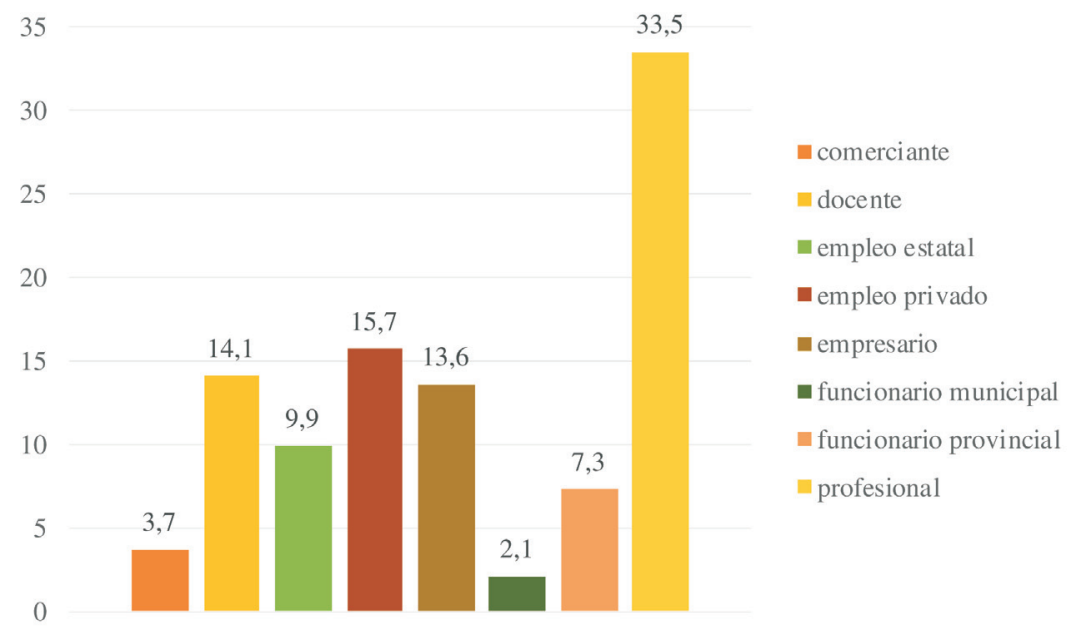

Fuente: Elaboración propia en base a datos de la autora. 
${ }^{11}$ Dos ejemplos de este tipo de trayectorias son los de Francisco Gutiérrez,

Secretario General de la Unión Obrera Metalúrgica de

Quilmes entre 1985 y 2005 y

Secretario de Interior de la

CGT; y Marta Maffei,

secretaria general de la

Confederación de

Trabajadores de la Educación

de la República Argentina por

tres periodos y miembro

fundador de la CTA.

${ }^{12}$ Una lista de los partidos y o alianzas que obtuvieron representación parlamentaria se presenta en el Apéndice

(Tabla 1A).

${ }^{13}$ La Alianza Frente para la

Victoria nucleó un conjunto variable de partidos entre 2007 y 2015 enla PBA.

${ }^{14}$ Para construir esta tabla se computó el cargo de mayor jerarquía ocupado, en cualquiera de las agrupaciones a las que hayan pertenecido, como así también dos tipos de participación informal (dirigente y dirigente local).

\section{Carreras políticas}

\footnotetext{
${ }^{15}$ Ejemplos de militancias diversas son los de Ramona Pucheta (dirigente del MIJD), Horacio Pietragalla Corti (nieto recuperado e integrante de Abuelas de Plaza de Mayo) y Mirta Pérez (fundadora de la Asociación de Víctimas de la Delincuencia luego de la muerte de su hijo). Antonio Rattin (ex jugador de Fútbol) y Mirta Tundis (periodista radial y televisiva) presentan como principal atributo previo la notoriedad pública.
}

muchos casos se trató de cargos de responsabilidad institucional (secretario/a general de sindicatos y centrales obreras/de trabajadores) por prolongados períodos vitales ${ }^{11}$.

Finalmente, un aspecto fundamental en términos de generación de vínculos y adquisición de competencias específicas, más directamente utilizables como recursos para acceder a una banca, es la militancia en estructuras partidarias. Es un dato difícil de consignar por distintos motivos: la falta de registros, la declaración voluntaria que no siempre incluye cargos de baja categoría, pero sobre todo dada la emergencia y desaparición de diversos partidos a lo largo del período $^{12}$. A lo que se suma que algunas coaliciones más o menos estables a través de las cohortes permiten la emergencia de fenómenos que superan las instancias electorales y se convierten en corrientes políticas de gran envergadura, pese a que no tienen correlato en organizaciones partidarias: el caso más arquetípico en el período es el Frente para la Victoria ${ }^{13}$. En ese marco son frecuentes las trayectorias que combinan participación en diversos partidos, y también modalidades de participación informales, sobre todo en el caso de distintos sectores del peronismo (dirigente, militante, referente).

Considerado a partir de la ocupación de cargos en estructuras partidarias ${ }^{14}$, es posible advertir que la amplia mayoría de quienes fueron DN ocupó al menos un cargo en alguna estructura partidaria a lo largo de su trayectoria (71\%). No obstante, el tránsito por estructuras partidarias no presenta una lógica uniforme: menos de la mitad de estos dirigentes (38\%) ocupó uno o más cargos jerárquicos (presidente, vicepresidente, integrante de mesas de conducción, en cualquiera de las escalas). Como contrapartida, la participación informal es la modalidad de relación con estructuras partidarias de casi una cuarta parte de los legisladores en el período (24\%). Si se parte del supuesto de que alcanzar un lugar en espacios de conducción en cualquiera de los tres niveles requiere un tránsito sostenido por las estructuras internas, es posible afirmar que una gran proporción de quienes fueron DN no requirió una trayectoria partidaria ascendente para acceder a una banca.

Afirmación que se refuerza considerando que hay un margen de individuos que no ocuparon cargos partidarios ni desempeñaron roles informales previamente a su llegada al cargo. Se trata de outsiders que tampoco ocuparon cargos públicos previos a ser incluidos en las listas de candidatos, ya sea en partidos mayoritarios como en agrupaciones más pequeñas y/o efímeras. Pese a ello su carácter de outsiders es relativo, ya que presentan otros atributos que colaboran a que accedan a una banca, como la participación en movimientos sociales, organizaciones asistenciales o civiles, y en menor medida notoriedad pública ${ }^{15}$.

Esta sección se ocupa de analizar las carreras políticas previas a la llegada al cargo de DN. La noción de carrera refiere a un recorrido en el cual se transitan distintos tipos de cargos públicos, ya sea en el mismo en distintos niveles de gobierno. Un primer indicador útil en este sentido es el primer cargo público ocupado, en tanto puerta de entrada al ámbito político en términos de actividad institucionalizada ${ }^{16}$ (Tabla 3).

De la evidencia se desprende que haber ingresado como DN es el modo más frecuente en este período en la PBA (37\%), es decir, más de la tercera parte llegó a formar parte de listas de candidatos por atributos distintos a la experiencia acumulada en cargos públicos. La magnitud de distrito puede operar como explicación de este fenómeno (Alles 2008), al ser la provincia que mayor contingente legislativo, como así también la distribución territorial que muchas veces hace primar la proximidad a la experiencia en cargos públicos. Para este 


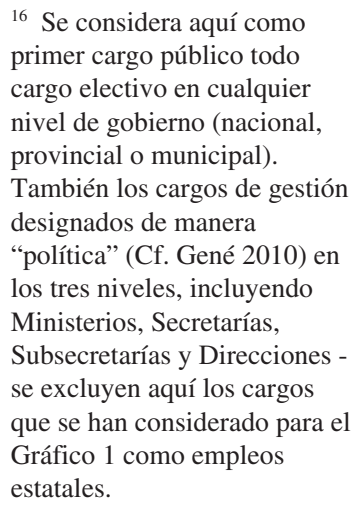

Tabla 3 - Primer cargo público ocupado, DN por la PBA (1999-2015)

\begin{tabular}{lc}
\hline Tipo de cargo & Porcentaje \\
\hline Electivos & 37,2 \\
Diputado Nacional & 2,2 \\
Senador Provincial & 5,6 \\
Diputado Provincial & 5,6 \\
Intendente & 18,2 \\
Concejal & \\
No electivos & 2,2 \\
Subsecretaría Nacional & 1,7 \\
Dirección Nacional & 4,8 \\
Otro Nacional & 1,7 \\
Ministro Provincial & 3,5 \\
Secretaría Provincial & 3,9 \\
Dirección Provincial & 2,2 \\
Otro Provincial & 4,3 \\
Secretaría Municipal & 1,7 \\
Subsecretaría Municipal & 4,3 \\
Dirección Municipal & 0,9 \\
Otro Municipal & 100 \\
Total & \\
\hline
\end{tabular}

Fuente: Elaboración propia en base a datos de la autora.

subconjunto de actores es aún más pertinente preguntarse qué atributos de sus trayectorias personales contribuyeron para que lograsen convertirse en representantes, análisis que se realiza en la siguiente sección.

Tomando en cuenta este dato inicial se presentan cinco tipos posibles de itinerarios de carrera (Lodola 2017), articulando los movimientos realizados según cargos y niveles: 1) sin carrera previa, 2) carrera binivel local-nacional, 3) carrera multinivel - con al menos un cargo en cada nivel de gobierno - 4) binivel provincial-nacional y 5) mononivel nacional. Los datos muestran que entre quienes desarrollaron una carrera previa el tipo más frecuente es binivel local-nacional (26.8\%), seguido por binivel provincial-nacional (18.2\%). Las carreras mononivel - que sólo podría ser nacional — representan un margen minoritario (7.8\%). Es decir que, en su gran mayoría, las carreras articulan dos niveles de gobierno, siendo predominante la articulación local-nacional. ¿Qué implica esto? Que las relaciones de cooperación y competencia en el nivel local son fundamentales llegar a formar parte de una lista de candidatos, sobre todo la relación con quienes se desempeñan en el Ejecutivo local, lugar al cual se accede también y sobre todo desde el trabajo territorial (Tabla 4).

Un dato relevante para analizar la articulación de escalas es el modo en que se organizan los recorridos. Como puede advertirse, excepto en las carreras mononivel nacional, las puertas de entrada más frecuentes son cargos legislativos: Concejal para las carreras binivel local-nacional (50\%) y multinivel (46\%), y Diputado Provincial para binivel provincial-nacional (26\%). Otro aspecto relevante es que las carreras multinivel son ascendentes, iniciándose sobre todo en cargos electivos - Concejal o Intendente - de nivel local (63\%). Es importante señalar que las modalidades de acceso más frecuentes son a 
Tabla 4 - Tipo de carrera política previa, DN por la PBA (1999-2015)

\begin{tabular}{lc}
\hline Tipo de carrera & Porcentaje \\
\hline Binivel local-nacional & 26,8 \\
Multinivel & 10,4 \\
Binivel provincial-nacional & 18,2 \\
Mononivel nacional & 7,8 \\
Sin carrera previa & 36,8 \\
Total & 100 \\
\hline
\end{tabular}

Fuente: Elaboración propia en base a datos de la autora.

través de cargos electivos, lo que implica transitar un proceso de construcción de la propia candidatura y un margen de autonomía en su ejercicio. Elementos que permiten matizar la difundida imagen de amateurismo de los legisladores argentinos (Jones et al., 2002) (Cuadro 1).

La carrera política puede analizarse también en función de la cantidad de cargos públicos ocupados, como un indicador de acumulación de destrezas y competencias específicas para el desarrollo de la actividad política. Es decir, una mayor cantidad de cargos y/o años de experiencia se asocia a mayor profesionalización, dado que se vivió durante más tiempo de y para la política (Weber 1998). En este sentido la acumulación de vasta experiencia previa es un rasgo compartido, ya que más de la mitad de las carreras muestran 5 o más cargos previos (52\%) (Tabla 5).

También en clave de acumulación de experiencia y/o adquisición de destrezas específicas, la distancia en años entre el primer cargo - es decir el ingreso al ámbito político - y la llegada al Congreso es un indicador que permite cuantificar la duración de las carreras. La distancia promedio es 10 años, con un amplio porcentaje de dirigentes cuyas carreras previas se extendieron por más de 15 años (40\%) (Tabla 6).

Cuadro 1 - Tipo de carrera política según primer cargo público ocupado, DN PBA (1999-2015) (\%)

\begin{tabular}{lcccc}
\hline Primer Cargo Público & Binivel local-nacional & Multinivel & Binivel provincial-nacional & Mononivel nacional \\
\hline Concejal & 50 & 46 & 0 & 0 \\
Dirección municipal & 13 & 8 & 0 & 0 \\
Dirección nacional & 0 & 0 & 2 & 17 \\
Dirección provincial & 0 & 4 & 19 & 0 \\
Diputado Provincial & 0 & 8 & 26 & 0 \\
Intendente & 15 & 17 & 0 & 0 \\
Ministerio Provincial & 0 & 0 & 10 & 0 \\
Otro municipal & 2 & 4 & 0 & 0 \\
Otro Nacional & 0 & 0 & 2 & 56 \\
Otro Provincial & 0 & 0 & 12 & 0 \\
Secretaría Municipal & 15 & 4 & 0 & 0 \\
Secretaría Provincial & 0 & 0 & 19 & 0 \\
Senador Provincial & 0 & 8 & 7 & 0 \\
Subsecretaría municipal & 7 & 0 & 0 & 0 \\
Subsecretaría Nacional & 0 & 0 & 2 & 22
\end{tabular}

Fuente: Elaboración propia. 
Tabla 5 - Cantidad de cargos públicos previos, DN por la PBA (1999-2015)

\begin{tabular}{lc}
\hline Cantidad & Porcentaje \\
\hline 2 & 20,3 \\
3 & 15,1 \\
4 & 12,0 \\
5 & 20,3 \\
6 & 10,4 \\
7 & 9,9 \\
8 & 4,7 \\
9 & 2,6 \\
10 & 4,7 \\
Total & 100,0 \\
\hline
\end{tabular}

Fuente: Elaboración propia.

Tabla 6 - Años entre ingreso a primer cargo público e ingreso a la banca, DN por la PBA (1999-2015)

\begin{tabular}{lc}
\hline Años & Porcentaje \\
\hline 4 o menos & 19,5 \\
5 a 14 & 39,6 \\
15 a 24 & 29,3 \\
25 a 34 & 7,9 \\
35 y más & 3,7 \\
Total & 100 \\
\hline
\end{tabular}

Fuente: Elaboración propia.

La evidencia presentada muestra dos grupos con perfiles diferenciados: por una parte, un amplio margen de dirigentes que accede a una banca sin haber construido una carrera política previa (37\%). Por otra, una mayoría de dirigentes que cuentan con vasta experiencia en cargos previos y largos períodos de participación en el ámbito político, habiendo transitado previamente cargos electivos en dos o más niveles de gobierno, entre los que destaca como espacio de tránsito (y socialización política y adquisición de destrezas) el nivel local.

\section{Carreras atípicas}

Este apartado retoma el análisis de las trayectorias personales de quienes inician su carrera como DN, a fin de describir atributos que pueden haber operado como recursos para esta modalidad de acceso particular al ámbito político. En cuanto a su origen social es posible advertir que este grupo de actores presenta características similares al perfil general: es más factible ingresar de este modo siendo varón (65\%), proveniente de un distrito mediano o pequeño de la PBA (57\%), en un rango etario que va de los 40 a los 59 años $(69 \%)$.

Con respecto a las credenciales educativas, en este grupo disminuye la formación universitaria y/o de posgrado (47\%) y aumenta la proporción de secundario completo (29\%). Entre quienes tienen título terciario o universitario también predomina la abogacía — aunque en menor medida (24\%) - y es 
también la Universidad de Buenos Aires la institución de mayor relevancia en cuanto a formación (35.5\%), seguida de la UNLP (18\%).

En cuanto a la ocupación previa predominan también las profesiones liberales en este grupo (30\%), aumentando levemente el margen de empleo privado $(24 \%)$. Respecto de la participación en organizaciones sociales aumenta considerablemente la participación en sindicatos $(41 \%)$, que constituye un recurso relevante sobre todo entre dirigentes de distintos sectores del peronismo. La participación en estructuras partidarias es un rasgo mayoritario también para este grupo (75\%), con un leve incremento en el porcentaje de ocupación de cargos jerárquicos $(42 \%)$.

Estos datos evidencian que el atributo que mayor incidencia tiene en el desarrollo de este tipo de trayectorias es la formación universitaria, puntualmente, el haber cursado la carrera de derecho en la Universidad de Buenos Aires, en tanto espacio de socialización y generación de vínculos personales. Otros dos rasgos de trayectoria personal que operan como recursos valiosos para acceder a una lista de candidatos a quienes no cuentan con experiencia en cargos públicos son la participación en sindicatos y haber ocupado cargos en estructuras partidarias, en especial cargos jerárquicos.

\section{Conclusiones}

Este trabajo apuntó a conocer las trayectorias personales y carreras políticas de un conjunto de actores relevantes: quienes se convierten en representantes legislativos, DN, por la PBA. Se intentó conocer qué aspectos de sus biografías pueden haber incidido en que llegasen a ocupar el cargo, partiendo del supuesto que ocupar una posición implica un trabajo activo, sostenido, de actores interesados en el juego político.

Entre sus principales atributos se pudo constatar una serie de rasgos típicos, coincidentes con descripciones previas sobre elencos políticos de la PBA. Una población mayormente masculina, de mediana edad, con niveles educativos elevados y orientada a profesiones liberales, en particular la abogacía graduados en la UBA y UNLP - constituye el tipo más frecuente. La nota distintiva en este grupo es, tal vez, el lugar de origen y la coincidencia con las carreras políticas posteriores: más de la mitad provienen de localidades medianas y pequeñas de la provincia, dato que permite inferir el peso de los vínculos sociales y territoriales en los modos de acceder al ámbito político y transitar carreras posteriores.

En cuanto a las carreras, y en relación con el lugar de origen, un elemento distintivo es la gran proporción de DN que accede a la banca sin contar con experiencia en cargos previos. Un grupo de actores diferenciado, que presenta rasgos similares al perfil típico en cuanto a atributos sociales (varones, universitarios, abogados egresados de la UBA y UNLP). Las instituciones universitarias estatales aparecen de este modo como un espacio de socialización privilegiado en términos de adquisición de vínculos duraderos que pueden operar como recursos valiosos para la llegada al cargo.

En este grupo de actores se advierten también la participación sindical y/o la participación en cargos jerárquicos en diversas estructuras partidarias como recursos valiosos para llegar a ocupar una banca, sobre todo entre quienes no comparten el perfil universitario o cuentan con formaciones distintas de la abogacía. Muy pocos son los casos de DN que no cuentan con alguno de estos atributos, contando con notoriedad y/o carisma como principal recurso.

Es decir, no se trata de outsiders en un sentido cabal, ni de dirigentes con rasgos atípicos excepto por la falta de experiencia previa. Es posible inferir que 
${ }^{17}$ El autor señala que sobre todo quienes encabezan las listas de candidatos (especialmente en la PBA) "no se comprometen con sus bancas: un alto porcentaje de ellos, sobre todo en elecciones de medio término, renuncia para ocupar otra posición que resulta más conveniente para su carrera personal o los intereses del partido. Esta nueva posición es, en general, otra candidatura, y en menor medida otro puesto ejecutivo. A estos los denominaremos ranas, por la acción de saltar hacia un nuevo punto que realizan al renunciar"

(Burdman 2010, p. 34) el acceso al ámbito político por el cargo de DN representa un caso típico en la PBA, lo que puede deberse a la alta tasa de rotación que permite la magnitud de distrito - y por ende la extensión de la lista de candidatos — como así también la lógica interna de nominación de los partidos. Como sugiere Burdman (2010) el cargo de DN no es particularmente atractivo para los políticos argentinos, como lo evidencian los casos de "ranas"17. Tal vez por este rasgo es un modo de acceso frecuente para quienes buscan ser integrados a los elencos legislativos en función de sus vínculos sociales y credenciales educativas, o quienes han acumulado suficientes recursos en otros espacios de participación.

El otro grupo, mayoritario de dirigentes, presenta carreras previas que son fundamentalmente de dos tipos: 1) binivel local-nacional y 2) binivel provincial-nacional. En ambos tipos las puertas de entrada más frecuentes son cargos legislativos (Concejal y Diputado Provincial respectivamente). Cargos electivos haber transitado un proceso de construcción de la propia candidatura y un margen de autonomía en su ejercicio: implican un trabajo activo y sostenido previo a convertirse en representantes. Este grupo de dirigentes cuenta además vasta experiencia en cargos públicos - tanto por la cantidad como por la extensión en años de sus carreras. Es decir que efectivamente convertirse en representante implica, para la PBA, un trabajo activo, sostenido, una persistencia en el juego político. Pertenencia, participación, acumulación de destrezas y competencias específicas, establecimiento de vínculos en distintos niveles de gobierno: se trata de actores que llegan a ocupar una banca con cierta autonomía a partir de los recursos que acumularon previamente.

Actores que llegan a una banca a partir de contar con recursos propios configuran un elenco legislativo relativamente independiente de lógicas estrictamente dirigenciales. Por el contrario, su propia participación es la que contribuye a la fisonomía que asumen los partidos y/o alianzas y a la dinámica de la competencia política en las distintas escalas. Actores que anclan su legitimidad en el nivel local, representando a un distrito provincial en la escala de gobierno nacional, los DN constituyen un punto de mira privilegiado para pensar la imbricación de las escalas en la política argentina. Las carreras de estos actores expresan una imbricación entre las distintas arenas, que se constituyen a partir de lógicas complementarias, multidireccionales, imposibles de definir a priori. Una agenda de investigación que abren estos resultados es el análisis de otros distritos subnacionales, a fin comparar modalidades de construcción de distintos elencos legislativos nacionales.

Cintia Rodrigo (cinrodrigo@gmail.com) es Magíster en Investigación Social y Doctora en Ciencias Sociales por la Universidad de Buenos Aires. Investigadora Asistente del Consejo Nacional de Investigaciones Científicas y Técnicas (CONICET) y docente del Departamento de Sociología de la Universidad Nacional de Mar del Plata (UNMdP). Vinculación Institucional: Consejo Nacional de Investigaciones Científicas y Técnicas/Centro de Estudios Históricos, Universidad Nacional de Mar del Plata, CONICET/CEHis-UNMdP, Mar del Plata, Bs. As., Argentina.

\section{Referencias}

Aelo, O., 2010. Grupos dirigentes y prácticas políticas. Dos fases del peronismo en la provincia de Buenos Aires, 1946-1955. In , ed. Las configuraciones provinciales del peronismo. Actores y prácticas políticas 1945-1955. La Plata: Instituto Cultural de la provincia de Buenos Aires.

Alles, S.M., 2008. Efectos del sistema electoral sobre la representación de mujeres. Argumentos y evidencia a partir del caso argentino (1983-2005). Revista SAAP, 3(2), pp.313-353.

Barreiro de Sousa Lemos, S. \& Leany, R., 2003. Carreras políticas en el Senado brasileño: Un estudio de las composiciones del Pleno y de la Comisión de Constitución, Justicia y Ciudadanía en la década de 90. Lateinamerika Analysen, 4, pp.3-30.

Becker, H., 1960. Notes on the Concept of Commitment. American Journal of Sociology, 66(1), pp.32-40. DOI: $10.1086 / 222820$

Bieda, T., 2015. ¿Quién eres? Carreras políticas de los legisladores encargados del control en Argentina (2001-2013). Revista SAAP, 9(2), pp.293-311. 
Borchert, J., 2009. Ambition and Opportunity in Federal Systems: The Political Sociology of Political Career Patterns in Brazil, Germany, and the United States (2009). In APSA Annual Meeting. Toronto.

Borner, J.; Caminotti, M.; Marx, J. \& Gustá, A.L.R., 2009. Ideas, presencia y jerarquías políticas. Claroscuros de la igualdad de género en el Congreso Nacional de Argentina. Buenos Aires: Prometeo.

Botero, F., 2011. Carreras políticas en América Latina. Discusión teórica y ajuste de supuestos. POSTdata, 16(2), pp.167-187.

Bourdieu, P., 2001a. El campo político. La Paz: Plural.

Bourdieu, P., 2001b. La representación política. In ___. El campo político. La Paz: Plural.

Burdman, J., 2010. Alfas, ranas y testimoniales: la cultura política de las elecciones legislativas de medio término en Argentina. POSTdata, 15(1), pp.33-74.

Caminotti, M., 2013. La representación política de las mujeres en el período democrático. Revista SAAP, 7(2), pp.329-337.

Caminotti, M., Rotman, S. \& Varetto, C., 2011. Carreras políticas y oportunidades 'generizadas' en la provincia de Buenos Aires, Argentina (1983-2007). Postdata, 16(2), pp.191-221.

Campomar, A.J. \& Suárez, B., 2014. El camino hacia el poder Analizando la carrera política de los gobernadores argentinos (1983-2011). Revista Mexicana de Ciencias Políticas y Sociales, 52(222), pp.369-390. DOI: 10.1016/s0185-1918(14)70222-3

Canelo, P., 2011. Acerca de la construcción de carreras políticas en la Argentina. Los senadores nacionales en 1973, 1983 y 1989. PolHis, 7, pp.140-153.

Cantón, D., 1966. El parlamento argentino en épocas de cambio: 1980, 1916 y 1946. Buenos Aires: Editorial del Instituto.

Dobry, M., 1988. Sociología de las crisis políticas. Madrid: Centro de Investigaciones Sociologicas/Siglo XXI.

Ferrari, M., 2001. Estrategias de reclutamiento y movilización de las élites políticas cordobesas, 1912-1930. Revista Historia UNISINOS, 5(4), pp.83-114.

Ferrari, M., 2005. En torno a la especialización en política. Notas sobre las trayectorias de los parlamentarios argentinos en tiempos de ampliación democrática. In Jorndas Interescuelas. Rosario.

Ferrari, M., 2008. Los políticos en la república radical. Prácticas políticas y construcción de poder. Buenos Aires: Siglo XXI.

Fillieule, O., 2015. Propuestas para un análisis procesual del compromiso individual. Insterticios, 9(2), pp.197-212.

García Arias, C., 2007. Cambio e institucionalización parlamentaria: la Cámara de Diputados argentina, 1983-1999. Tesis de Doctorado. Santiago de Compostela: Universidad Santiago de Compostela.

Gauja, A., 2013. The Politics of Party Policy From Members to Legislators. Hampshire: Palgrave Macmillan.

Gaxie, D., 2004. La democracia representativa. Santiago: LOM Ediciones.

Gené, M., 2010. En torno a los profesionales de la política. Trayectorias, prácticas y destrezas en el ejercicio del poder político desde el Estado. Revista Perspectivas de Políticas Públicas, 1, pp.85-107. DOI: 10.18294/rppp.2011.645

Giorgi, G., 2014. Los factores extrapolíticos de la carrera política: una aproximación a las sociabilidades de los ministros de la Nación en Argentina (1854-2011). Revista de Ciencia Política, 52(2), pp.243-275.

Heredia, M., 2015. Cuando los economistas alcanzaron el poder (o cómo se gestó la confianza en los expertos). Buenos Aires: Siglo XXI.

Joignant, A., 2012. Habitus, campo y capital. Elementos para una teoría general del capital político. Revista Mexicana de Sociología, 74(4), pp.587-618.

Jones, M.P.; Saiegh, S.; Spiller, P.T. \& Tommasi, M., 2002. Amateur Legislators-Professional Politicians: The Consequences of Party-Centered Electoral Rules in a Federal System. American Journal of Political Science, 46(3), pp.656-669. DOI: $10.2307 / 3088406$.

Landau, M., 2012. La profesión política en Buenos Aires. Apuntes para el estudio de los perfiles y trayectorias de los concejales y diputados de la ciudad (1983-2011). In IV Jornadas de Estudios Políticos. General Sarmiento.

Landau, M., 2016. Las carreras políticas de los legisladores porteños: profesionales, líderes partidarios y militantes periféricos", en $10^{\circ}$ Congreso Asociación Brasileña de Ciencia Política. Belo Horizonte.

Lascurain, M.C., 2011. Cambios en la representación política. Un abordaje a partir de los perfiles de los gobernadores peronistas de la provincia de Santa Fe entre 1983 y 2007. Papeles de Trabajo, 5(8), pp.117-133.

Levita, G., 2015. La política como profesión: perfiles y tipos de trayectorias de los senadores argentinos. TELOS, 17, pp.38-57.

Levitsky, S., 2005. La transformación del justicialismo. Del partido sindical al partido clientelista. 1983-1999. Buenos Aires: Siglo XXI.

Lodola, G., 2009. La estructura subnacional de las carreras políticas en Argentina y Brasil. Desarrollo Económico, 49(194), pp.247-286.

Lodola, G., 2017. Reclutamiento político subnacional. Composición social y carreras políticas de los gobernadores en Argentina. Colombia Internacional, 91, pp.85-116. DOI: 10.7440/colombiaint91.2017.03

Marx, J.; Caminotti, M. \& Borner, J., 2007. Las legisladoras: cupos de género y política en Argentina y Brasil. Buenos Aires: Instituto Di Tella.

Offerlé, M., 2011a. Los oficios, la profesión y la vocación de la política. PolHis, 7, pp.84-99.

Offerlé, M., 2011b. Perímetros de lo político. Contribuciones a una socio-historia de lo político. Buenos Aires: Antropofagia.

Ollier, M., 2010. Atrapada sin salida. Buenos Aires en la política nacional. 1916-2007. San Martin: UNSAM.

Ortiz de Rozas, V., 2011. Las formas de reclutamiento del personal político, una vía de entrada al estudio del régimen político provincial. Santiago del Estero (1999-2009). Revista Perspectivas de Políticas Públicas, 1(1), pp.133-159. DOI: 10.18294/rppp.2011.647 
Ortiz de Rozas, V., 2012. El régimen político provincial a través de las elecciones y las trayectorias del personal político. La pauta del gran elector en Santiago del Estero (1999-2010). Tesis de Maestría. San Martín: Universidad Nacional de San Martín.

Rehren, A., 2001. La presidencia y el parlamento como instituciones representativas: los casos de Argentina, Chile y Francia. Revista de Ciencia Política, 21(2), pp.122-151.

Rodrigo, C., 2014. Actores, relaciones y escaños. Apuntes para el estudio de las carreras políticas de los diputados nacionales por la Provincia de Buenos Aires. ESTUDIOS, 32, pp.135-148.

Rotman, C. etal., 2009. Entre senderos y ambiciones. Las carreras políticas en la Provincia de Buenos Aires (1983-2007). In Congreso Nacional de Ciencia Política SAAP. Santa Fe.

Rotman, S. \& Varetto, C., 2015. Se hace camino al andar. Las carreras políticas en la Provincia de Buenos Aires (1983-2011). In M. Escolar \& J. Abal Medina, eds. Modus vivendi. Política multiniverl y Estado federal en Argentina. Buenos Aires: Prometeo.

Samuels, D., 2011. Ambición política, reclutamiento de candidatos y política legislativa en Brasil. POSTdata, 16(2), pp.281-307.

Schlesinger, J., 1966. Ambition and Politics: Political Careers in the United States. Chicago: Rand McNally.

Serna, M., 2005, Las vías hacia el poder político. Bases sociales y carreras parlamentarias. In E. Mazzei, ed. El Uruguay desde la Sociología IV. Montevideo: UDELAR.

Serna, M., 2009. La composición de la élite política uruguaya: circulación y reconversión en democracia. In $33^{\circ}$ Encontro Anual da Anpocs. Caxambú.

Serna, M., ed., 2012. Giro a la izquierda y nuevas elites en Uruguay. ¿Renovación o reconversión? Montevideo: Universidad de la República.

Simison, E., 2013. ¿Diputados de quién? Selección de candidatos legislativos en Argentina (2003-2013). In VII Jornadas de Jóvenes Investigadores, Instituto de Investigaciones Gino Germani. Buenos Aires.

Simone, N., 2015, Los diputados de la reconstrucción democrática argentina 1983-1989: ¿amateurismo o carrera legislativa?”. In XII Congreso SAAP. Mendoza.

Suárez-Cao, J.; Batlle, M. \& Wills-Otero, L., 2017. El auge de los estudios sobre la política subnacional latinoamericana. Colombia Internacional, 90, pp.15-34.

Suárez, A.J., 2016. Aproximación a los perfiles de los vicegobernadores argentinos (2003-2015). Analecta Política, 6(10), pp.93-114. DOI: 10.18566/apolit.v6n10.a05

Weber, M., 1982. Escritos políticos. México: Folios.

Weber, M., 1998. La política como vocación. In R. Aron, ed. El político y el científico. Madrid: Alianza.

\section{Become a Legislator: Biographies and Political Careers of Buenos Aires Province MPs}

ABSTRACT Introduction: This paper aims to know the how some political actors became legislators, asking about the key factors to their success. The article analyzes one specific political cast: national MPs of Buenos Aires Province, Argentina. It describes two complementary dimensions: their biographies and their political careers. The main objective is to know if there are typical ways to combine both dimensions in this political district. The central assumption is that not only political parties-or their leaders-are who choose candidates. Also-and above all-politician collaborating in unstable networks of cooperation and competence shapes party structures and / or electoral alliances for successive contests. Methods: Data proceed from an original database of biographies and political trajectories of national MPs from Buenos Aires Province (1999-2015). Results: Results shows two typical ways of combination between biographies and career. On one hand, becoming MP is a frequent way of access for those who want to be included in political casts according to their social bonds and educational credentials, or those whom had accumulated enough resources in different provincial spaces of participation. On the other hand, represents an arrival point for actors who had developed a long political participation, accumulating skills and establishing multilevel governmental scales bonds. Discussion: The way in which biographies and career articulate within this group shows actors with relative autonomy degrees, based on an active, long and sustained work in different scenarios of participation. Owning their resources enable them to form their legislative cast relatively independent of the logic of leadership strictly. Contrary, their own participation contributes to shapes parties and/or alliances, shaping political competition at different government levels. MPs are actors who anchor their legitimacy at local level, representing to a province, to develop their role at national level. Their analysis allows to know about the imbrication of political levels in Argentina. These results open as a research agenda the analysis of other subnational districts, to compare different ways to construct MP casts.

KEYWORDS: political path; subnational political career; national MPs; political representatives; Buenos Aires Province.

This is an Open Access article distributed under the terms of the Creative Commons Attribution Non-Commercial License which permits unrestricted non-commercial use, distribution, and reproduction in any medium provided the original work is properly cited. 


\section{Apéndice}

Tabla 1A - Partidos y Alianzas que obtuvieron bancas de DN, PBA (1999-2015)

\begin{tabular}{|c|c|c|}
\hline Año & Partido o Alianza & Bancas \\
\hline \multirow[t]{4}{*}{1999} & Alianza para el Trabajo, la Justicia y la Educación & 16 \\
\hline & Alianza Concertación Justicialista para el Cambio & 16 \\
\hline & Acción por la Republica & 2 \\
\hline & Unidad Bonaerense & 1 \\
\hline \multirow[t]{5}{*}{2001} & Partido Justicialista & 18 \\
\hline & Alianza Frente Polo Social & 4 \\
\hline & Alianza ARI & 4 \\
\hline & Alianza para el Trabajo, la Justicia y la Educación & 7 \\
\hline & Unidad Federalista & 2 \\
\hline \multirow[t]{5}{*}{2003} & Partido Justicialista & 19 \\
\hline & Alianza Frente Popular Bonaerense (FroPoBo) & 5 \\
\hline & Alianza ARI & 4 \\
\hline & Unión Cívica Radical & 4 \\
\hline & Alianza Acción Federalista para Buenos Aires & 3 \\
\hline \multirow[t]{5}{*}{2005} & Alianza Frente Justicialista & 8 \\
\hline & ARI & 3 \\
\hline & Unión Cívica Radical & 3 \\
\hline & Alianza Propuesta Republicana & 3 \\
\hline & Alianza Frente Para la Victoria & 18 \\
\hline \multirow[t]{4}{*}{2007} & Alianza Frente Para la Victoria & 20 \\
\hline & Alianza Frente Coalición Cívica & 9 \\
\hline & Alianza Unión - PRO & 4 \\
\hline & Unión Cívica Radical & 2 \\
\hline \multirow[t]{4}{*}{2009} & Alianza Nuevo Encuentro & 2 \\
\hline & Alianza Unión Pro & 13 \\
\hline & Alianza Acuerdo Cívico y Social & 8 \\
\hline & Alianza Frente Justicialista Para la Victoria & 12 \\
\hline \multirow[t]{5}{*}{2011} & Alianza UDESO & 3 \\
\hline & Frente Popular & 2 \\
\hline & Compromiso Federal & 2 \\
\hline & Alianza Frente Amplio Progresista & 5 \\
\hline & Frente Para la Victoria & 22 \\
\hline \multirow[t]{5}{*}{2013} & Frente Progresista Cívico y Social & 4 \\
\hline & Frente Para la Victoria & 12 \\
\hline & Frente Renovador & 16 \\
\hline & Frente de Izquierda y los Trabajadores & 1 \\
\hline & Unidos por la libertad y el trabajo & 2 \\
\hline
\end{tabular}

Fuente: Elaboración propia, en base a datos de la Dirección Nacional Electoral. 